\title{
The information provided at the antenatal clinic regarding foetal diagnostics -how is it perceived? A qualitative interview study
}

Ylva Carlsson ( $\sim$ ylva.carlsson.2@obgyn.gu.se)

Sahlgrenska University Hospital

Pernilla Strömbäck

University of Gothenburg

Ingela Lundgren

University of Gothenburg

\section{Research Article}

Keywords: Foetal diagnostics, prenatal testing, information, antenatal clinic

Posted Date: January 4th, 2021

DOl: https://doi.org/10.21203/rs.3.rs-134178/v1

License: (1) (i) This work is licensed under a Creative Commons Attribution 4.0 International License.

Read Full License 


\section{Abstract}

Background: Prenatal testing is voluntary and should be offered to all pregnant women in combination with sufficient information. Earlier studies have shown that pregnant women often felt the information given at the antenatal clinics about foetal diagnostics was lacking. Since new methods in foetal diagnostics are introduced into routine health care, there is an increased need for adequate information.

The aim of this study was to examine how pregnant women and their partners perceive the information given at the antenatal clinic regarding foetal diagnostics, as well as to increase the understanding of how this information can be improved.

Methods: A qualitative interview study was conducted in the Gothenburg area in Sweden. Ten women and seven partners expecting their first child were interviewed. The data was analysed using content analysis with an inductive approach.

Results: The interview data generated three main categories and ten subcategories. The first category, 'Diversity in the information perceived,' concerned differences in the level of information perceived regarding voluntariness, the methods' purpose and the possibility of abnormal findings. The second category, 'Varying needs related to improved information,' concerned the parents' needs related to thorough information and pre-existing knowledge. The third category, 'The midwife has a great impact on the information perceived,' concerned sufficient and insufficient susceptibility and time to ask questions as well as varying experiences of the midwife's attitude.

Conclusions: Although previous research have already pointed out that information regarding foetal diagnostics is lacking, this study shows that there is still room for improvement. This is even more urgent now with new methods being introduced, which can make choices concerning foetal diagnostics even more complicated for the pregnant woman. The given information should be explicit concerning purpose, limitations and the voluntariness of prenatal testing. Sufficient time for questions and discussion was important to many who were interviewed. The diversity in answers among the participants in the study highlights the importance of considering the level of the parents' pre-existing knowledge and their individual thoughts and questions and that it is important to adapt the information to the individual woman and partner.

\section{Background}

The purpose of foetal diagnostics is to preserve the woman's autonomy concerning her pregnancy and to optimise the medical care both during pregnancy and childbirth, by identifying foetal malformations, genetic aberrations and pregnancy complications. In Sweden, midwives are professionally responsible during normal pregnancy and birth (1). Essentially all women attend the free-of-charge antenatal care clinic during their pregnancy according to national guidelines and are informed in gestational week 5-8 about foetal diagnostics by a midwife. Some midwives at the hospitals work with ultrasound diagnostics scans after special education and training. If something abnormal is detected the woman is then referred 
to a foetal medicine specialist or a specialist in obstetrics and gynaecology. Currently available methods in the Swedish setting include an ultrasound diagnostics scan, a so-called combined test (consisting of a combination of ultrasound and biochemical methods), non-invasive prenatal testing (NIPT) as well as invasive diagnostic testing of the amniotic fluid (amniocentesis) and placenta (chorionic villus sampling). The combined test is offered free-of-charge to women over 35 years of age and NIPT is offered free-of-charge if the combined test show an increased risk for a chromosomal aberration. Both the combined test and NIPT are offered for a fee by private outpatient clinics. Swedish health regulations state that each pregnant woman should be offered information about these methods if she so wishes and it is of outmost importance how this information is conveyed so that the voluntariness is clear to the woman (2).

Women often turn to newspapers, television, family and friends as sources for general information regarding foetal diagnostics (3). The Swedish Agency for Health Technology Assessment and Assessment of Social Services (SBU) stated in their 1998 report that women are greatly influenced by the information provided by the antenatal clinic and that the information is often insufficient, since the voluntariness of undergoing examinations is not sufficiently emphasised and because it is often not clearly stated that the ultrasound diagnostics scan is a form of foetal diagnostics that could reveal serious malformations (4). Previous studies have shown that up to two-thirds of pregnant women in Sweden perceive that the second trimester ultrasound diagnostics scan was a compulsory part of the antenatal care and in line with the SBU report, one-third of the women could not recall being informed by any professional that malformations could potentially be detected during the scan (5). Furthermore, in another study only $57 \%$ of the participating women considered themselves informed about the ultrasound diagnostics scan at any antenatal care visit (6). Women also reported that they were unclear about the purposes for which an ultrasound diagnostic scan was performed as well as the technical limitations of the procedure, and had expectations that exceeded both the purpose and capability of the examination (6-8). However, after birth, a vast majority of the participating women reported feeling satisfied with the information about why and how the second trimester ultrasound diagnostics scan was performed (9). Only $58 \%$ reported that they had received sufficient information about possible risks of the procedure (9).

The studies cited above concern the quality of information given about the second trimester ultrasound diagnostics scan, but the information provided regarding other foetal diagnostics methods such as the combined test, NIPT and invasive testing is also important to consider. Furthermore, the introduction of new foetal diagnostic methods may require provision of broader and more comprehensive information at the antenatal clinics, compared with pre-existing diagnostic methods. A risk with the introduction of new methods of foetal diagnostics is that they may be unquestionably accepted by parents who long for reassurance of a normal pregnancy (10). NIPT was introduced in foetal diagnostics 2011 and is based on the analysis of free foetal DNA in the blood of the pregnant woman. The test aims at screening and detecting the most common chromosomal aberrations (11-13). A non-invasive blood test is easier to carry out compared to a combined test or an invasive procedure, and hence, there is an increased risk that women accept this test without giving it sufficient thought and consideration. This increases the burden 
of responsibility on the antenatal clinics to provide thorough information and guidance, to ensure that parents are able to make well-informed decisions in order to avoid that the national healthcare system itself, and hence what kind of foetal diagnostics that are offered free-of-charge, might influence the choice of the pregnant woman and the partner (14).

The aim of this study was to explore how parents today perceive the information provided at the antenatal clinic regarding foetal diagnostics. Furthermore, we also aimed to increase the understanding of how the information of foetal diagnostics provided in the antenatal clinic can be improved.

\section{Methods}

\section{Study site and participants}

Women expecting their first child were randomly selected from the reservation list for a second trimester ultrasound diagnostics scan at the Department of Obstetrics and Gynaecology at Sahlgrenska University Hospital, Gothenburg, Sweden. In the Gothenburg area less than $2 \%$ of pregnant women attend a privately funded antenatal clinic. Most pregnant women in the area (96-98\%) attend the second trimester diagnostics ultrasound scan at Sahlgrenska University Hospital.

Because of the interview study design, participants were required to be able to express themselves understandably in spoken Swedish (written Swedish was not a requirement). Information letters about the study were sent to the women before their second trimester ultrasound diagnostics scan, but after their first visit with the midwife at the antenatal clinic. Thus, women were not aware of the study when being informed about foetal diagnostics at their first visit at the antenatal clinic. The study information letter contained contact information offering the women and their partners the possibility to ask further questions about the study. Upon arrival for their second trimester ultrasound diagnostics scan, women and their partners (if applicable) were asked if they would like to participate in the study and if so, they signed the informed consent form and the interview took place at the same visit as the second trimester ultrasound diagnostics scan.

\section{Qualitative interviews and data analysis}

Semi-structured interviews were performed. The researcher prepared four wide questions in advance, which the interviewees answered in their own way, conveying the information they felt was relevant (Table 1). 
The prepared semi-structured interview questions.

\section{What information did the interviewee perceive from the midwife at the antenatal clinic regarding the second trimester ultrasound diagnostics scan?}

2. Did the interviewee perceive that the second trimester ultrasound diagnostics scan is voluntary?

3. What information did the interviewee from the midwife at the antenatal clinic regarding other methods used in foetal diagnostics, besides the second trimester ultrasound diagnostics scan?

4. Did the interviewee miss any piece of information about foetal diagnostics, and if so, which information did they wish had been provided by the midwife at the antenatal clinic?

One researcher, who were not a care-giver, performed all interviews and the researcher could add spontaneous questions and the order of the prepared questions could be changed within each interview. The interviews were recorded and then transcribed into written documents for analysis. All interviews $(n=$ 17) were conducted during a two month period. The length of the interviews varied from 11.5 to 37 minutes.

A qualitative content analysis method was used (15) and conducted by two of the researchers together, in an inductive manner to allow an unbiased analysis of individuals' narratives of their experiences. To organise the collected data, the written material from the transcribed interviews was coded based on approximately two hundred selected condensed meaning units. The codes were read repeatedly and closely reviewed while being sorted into different subcategories. The subcategories were thoroughly compared and merged into main categories (Table 2).

Table 2

Process for subcategory and category creation from condensed meaning units.

\section{Condensed \\ Codes \\ Subcategories \\ Category}

\section{meaning units}

..she said: "if you have any questions, just give us a call".

...there was very little time for information or questions and that was not so good.

... I thought that she was completely neutral. She even said that "I have to inform you about this, but I will not have any opinion about your decision.

I got the feeling that she didn't think that we needed to do it...
A

receptiveness for questions

Not enough time for questions

The attitude of the midwife was perceived as neutral

The attitude of the midwife was not perceived as neutral
Sufficient and insufficient susceptibility and possibility to ask questions The midwife has a great impact on the information perceived 
Approximately two hundred condensed meaning units were extracted from the transcribed text material. Codes were identified from the condensed meaning units and sorted into subcategories. The subcategories were thoroughly compared and merged into main categories.

\section{Results}

The age range of the interviewed parents was 23-37 years of age (median 29 years, average 30.6 years). The partner of the pregnant woman participated in 7 of the 10 interviews and the couple were in all these cases interviewed together. Interviewed parents were born in five different countries: Sweden, Denmark, Finland, Slovenia, and Bosnia.

Inductive analysis of the interview data generated three main categories composed of two to four subcategories each (total of ten subcategories) (Table 3).

Table 3. Main categories and subcategories generated by interview data.

\begin{tabular}{|llll|}
\hline Categories & $\begin{array}{l}\text { 1. Diversity in the } \\
\text { information perceived }\end{array}$ & $\begin{array}{l}\text { 2. Varying needs } \\
\text { related to } \\
\text { improved } \\
\text { information }\end{array}$ & $\begin{array}{l}\text { 3. The midwife has a great } \\
\text { impact on the information } \\
\text { perceived }\end{array}$ \\
\hline Subcategories & $\begin{array}{l}\text { 1.1. Information perceived } \\
\text { on the different methods } \\
\text { of foetal diagnostics }\end{array}$ & $\begin{array}{l}\text { 2.1. Varying need } \\
\text { of more thorough } \\
\text { information }\end{array}$ & $\begin{array}{l}\text { 3.1. Varying opinions with } \\
\text { respect to the midwife's } \\
\text { attitude }\end{array}$ \\
\hline $\begin{array}{l}\text { 1.2. Varying information } \\
\text { on possible abnormal } \\
\text { findings and potential } \\
\text { consequences }\end{array}$ & $\begin{array}{l}\text { 2.2. Varying pre- } \\
\text { existing } \\
\text { knowledge in } \\
\text { order to ask } \\
\text { questions }\end{array}$ & $\begin{array}{l}\text { 3.2. Sufficient and insufficient } \\
\text { susceptibility and possibility to } \\
\text { ask questions }\end{array}$ \\
$\begin{array}{ll}\text { 1.3. Perceivement of } \\
\text { voluntariness }\end{array}$ & $\begin{array}{l}\text { 3.3. Requests of more clarity } \\
\text { and a need to look for own } \\
\text { information }\end{array}$ \\
& & $\begin{array}{l}\text { 3.4. A balance regarding how } \\
\text { much information should be } \\
\text { given to decrease worry among } \\
\text { parents }\end{array}$ \\
\hline $\begin{array}{l}\text { 1.4. Varying opinions } \\
\text { about oral and written }\end{array}$ & & \\
information & & \\
\hline
\end{tabular}

The three main categories (numbered 1-3) and 10 subcategories (sub-numbered below each main category) generated by inductive analysis of the interview data.

\section{Diversity in the information perceived}


A wide variation was reported in the amount and quality of information concerning foetal diagnostics that parents perceived at the antenatal clinics. This was true regarding different types of diagnostic methods, consequences, risks and the voluntariness of prenatal testing procedures.

\subsection{Information perceived on the different methods of foetal diagnostics}

When questioned about the second trimester ultrasound diagnostic scan, some parents stated that they had received very little information, while some also said that they had not realized that the second trimester ultrasound diagnostics scan is a form of foetal diagnostics. Most parents stated that the second trimester ultrasound diagnostics scan was performed in order to check that everything was alright with the baby. Several parents stated that they had perceived that the foetus was measured during the second trimester ultrasound diagnostics scan. Some of these parents had also perceived that different bones as well as the head of the foetus were measured, to estimate the birth date of the child more exactly. A few parents believed the number of foetuses in the womb was checked during the second trimester ultrasound diagnostics scan. Only a few parents perceived that they had received information about how the second trimester ultrasound diagnostics scan was carried out in practice.

Knowledge about the combined test varied among the parents. Some parents stated that they had not received any information, others felt that they had been sufficiently informed, while others could not at all or only vaguely remember the term "combined test" when it was mentioned during the interview. Information that parents had comprehended concerning the combined test was that a combined test is done by taking blood tests together with an ultrasound examination, which is not dangerous for the baby, and one's age is taken into consideration. A few parents further explained that one must pay for the test oneself if under a certain age, and that the combined test is first and foremost offered to older parents. They believed that it can be wise to take the test if older than 35 years of age. Some parents recalled that the blood test that is part of the combined test should be taken in gestational week 9 or 10 , that the combined test is a way to look at the chromosomes for Down syndrome, to check if there are any hereditary diseases, and show the probability for chromosome defects. One parent said: "There is a risk of about one in two hundred of Down syndrome after the age of 35. The combined test does not give a definite answer; there can be a need for more tests after the combined test."

Regarding the amniocentesis method, some parents did not recall that they had been provided any information about the examination, while others felt that they had been sufficiently informed about it. One couple said "... I think she informed us very well about what it implied... It was especially the statistics we looked at. That she presented the risks and the advantages and what you can feel about the result you get... She felt safe and it felt like she knew her thing...". As well as with the second trimester ultrasound diagnostics scan and the combined test, the knowledge about invasive diagnostic testing retained by the parents also varied. According to the parents, if the combined test showed a risk of everything not being alright with the foetus, then the next step is to decide whether to proceed with 
amniocentesis. One parent said: "The amniocentesis is something that you are offered if it is too late to do the combined test." Furthermore, the parents expressed that there are risks with undergoing the amniocentesis, including a risk of having a miscarriage. "You enter with a needle through the navel and extract water," one parent explained. The parents also said that amniocentesis can show whether the baby has Down syndrome, and that it is more common to do amniocentesis after the age of 35 , since there is a greater risk that something is wrong with the baby if the mother is older. Some parents said that their midwife had shown them the statistics of how great the risk is with taking the test and discussed this rather than the risk that someone in the woman's age would have a child with the diseases that can be detected with the amniocentesis. These parents appreciated this kind of information and thought that it was very helpful when it came to decision-making regarding foetal diagnostics.

A few parents had not perceived that they had received any separate or additional information about the different methods used in foetal diagnostics, besides the second trimester ultrasound diagnostics scan. These parents stated that the methods in excess of the second trimester ultrasound diagnostics scan were designated as a group of other tests or mentioned as "foetal diagnostics" in general. The parents perceived that these tests could be done to see that the baby was alright, e.g., that there was nothing wrong with the baby. The parents had perceived that in order to get access to those tests one must make an appointment for oneself, pay out-of-pocket, and that such tests are much more common to do when one is older. The NIPT was only mentioned by one interviewed person, who had not perceived any information about it from the midwife at the antenatal clinic, but rather from a relative with knowledge within the field of medicine.

\subsection{Varying information on possible abnormal findings and potential consequences}

Several parents stated that they had not perceived that the midwife at the antenatal clinic prepared them for the possibility that the second trimester ultrasound diagnostics scan could reveal abnormal findings and what would happen if so. Some of the parents who did not get this information said that they were aware of the possibility of abnormal findings, though some parents wished that they had been more prepared for the possibility. One interviewed person said: "I just wonder, that if something would have been wrong, what preparedness is there to handle that?... Am I just going to walk out the door and go home?" One interviewee said that the midwife did not prepare the couple for abnormal findings orally, but that it was stated in the written information they had perceived, and that the examination could give difficult information and hence they were advised not go to there alone. Another interviewed person stated that she was so stressed during the visit with the midwife at the antenatal clinic, that she believed that the midwife for that reason chose not to mention the possibility of the second trimester ultrasound diagnostics scan revealing abnormal findings, and furthermore that she felt that the midwife made the right decision by doing so. Some parents did understand that the second trimester ultrasound diagnostics scan could reveal abnormal findings and received information about what would happen in such a case. One interviewed person said that the couple was informed that they would be called back to the midwife 
to talk if the second trimester ultrasound diagnostics scan showed abnormal findings. The couple was also informed that the staff who perform the second trimester ultrasound diagnostics scan is very thorough and careful and that if it would not be possible to see everything you need to see during the first examination, the couple would be called back for another ultrasound. This couple was also told that no one would say that everything is fine if it was not. "You do want to know this. I mean, there still is a risk that everything is not normal. And then you really want to know, before you end up in that situation." Yet the same couple also emphasised that it is a balance not to talk too much about the possibility of abnormal findings to avoid anxiety among parents. Some parents stated that they felt rather calm at the visit with the midwife at the antenatal clinic, but that the anxiety came later, when the date of the second trimester ultrasound diagnostics scan was approaching. One interviewee said, "The last week I have felt a bit worried about what they might see. Are you able to see if something is extremely wrong?"

Regarding the combined test and invasive testing, the parents had perceived varying information about the choices and consequences that can come with taking the tests. One interviewed person said, "...She mentioned that the results you get might influence the way you feel about the pregnancy or the baby. If you want to keep the pregnancy or not, if it is not well." Some parents related that their midwife mentioned that if you take the combined test, you should be prepared to decide whether you want to continue with further testing, if the test detects abnormal findings. Other parents did not mention that they had gotten any information about the combined test. Not all parents felt that they had perceived information about the invasive testing, such as amniocentesis or chorionic villus sampling, and the consequences of the tests, while some parents felt that they had perceived such information. One interviewed person, who had considered doing amniocentesis, stated, ".../ think she informed very well about what it meant. The fact that she mentioned... well ... what are you going to do with the information you get."

\subsection{Perceivement of voluntariness}

Several parents had understood that the second trimester ultrasound diagnostics scan is voluntary. Other parents said that they had not perceived such information, but still stated that they understood that the examination was voluntary or that they had not given it much thought because it still was something they really wanted to do. One interviewed person said: "... she (the midwife) said that it was voluntary, but otherwise I think it merely was a matter of booking a date." One interviewed person said that she thinks that it would be preferable if the midwife had mentioned the voluntariness: "As a Swedish citizen I assume that the medical care I am offered is voluntary. For my own good, just as it is voluntary to take the pap smear test every three years or so. ... There is not really anyone who has told me that it is voluntary. ... I think that it would have been good if they would have done that." Regarding the second trimester ultrasound diagnostics scan, one couple expressed that it is important not only that the midwife gives information about the voluntariness of a test, but also to inform about the advantages and disadvantages with the test. It is important to elucidate all essential information, not only to express that it is the parents' own choice. Regarding the combined test the couple felt that it was wrong that the 
midwife asked them if they were interested in doing the combined test, before she had given them information about it. Afterwards they felt like they said no to an examination about which they had not obtained enough information. They also wished that they had gotten information about invasive testing along with the information about the combined test, since these are tests that can follow the combined test and therefore also are relevant. In conclusion, a clear wish of getting the whole picture presented and not only making the voluntariness clear was expressed.

\subsection{Varying opinions about oral and written information}

Several parents mentioned that they had received written information about foetal diagnostics in the form of either pamphlets, separate papers, or in a book called, "To expect a child". Some parents stated that they had not read the information they had been provided; others felt that they would have appreciated more written information. One interviewee said "... Maybe you could have more brochures about this subject and more information about the second trimester ultrasound diagnostics scan in particular, in order to be more prepared about what the examination includes and what is going to happen... Then you can bring it home with you and read it in peace and quiet at home and also before you come here." Several parents pointed out the positive aspect of being able to read the information at home afterwards. They reflected that it can be a lot of information to take in orally at the antenatal clinic and one cannot be sure that it's being remembered correctly. Some parents also believed that it was also good to be able to refresh their memory at the time of the examination. Some parents felt that the written information was too basic and others felt that it was too difficult to understand. One interviewed person who felt the need to look for complementary information herself stated, "...It was pretty superficial. You almost just got more questions... It is a pretty basic description...". One of the parents who felt that the written information was too difficult to understand said, "... There is a lot of doctor's terms and things like that, so you will probably not quite understand everything you read... Why do you want to check for chromosomal aberrations? What could that lead to? And why?"Some of the parents considered it to be best to get the information both orally and in writing, while others thought that oral information was enough. One couple said, "Orally is enough... If you have any questions you ask straight away and get your answers immediately."

\section{Varying needs related to improved information}

A great difference regarding need of thorough information and varying pre-existing knowledge were observed in the interviews.

\subsection{Varying need of more thorough information}

Some parents were totally satisfied with the information provided by the midwife at the antenatal clinic about foetal diagnostics, while others felt that the information was insufficient. These parents wished for more information about how the examination was carried out, and more information at the time point of 
the examination. Furthermore, these parents were also interested in learning more about what was possible to see and what the midwife was going to look at, including details like the fetal aorta and valves. One interview person said, "It seems like something that is so obvious since everybody does the second trimester ultrasound diagnostics scan, yes, but I have never thought about what it is that you do? So, more information about that, but maybe I also should have conveyed that I needed it."

While some parents felt that they had gotten satisfactory information about the combined test, other parents felt that the information was not enough or had trouble recalling if they had received any information about the test at all. Some of the parents had not perceived that an ultrasound examination is a part of how the combined test is carried out. One parent further wished that they would have been informed about what a combined test really is; which information you can get by taking a combined test, which proteins are scanned for in the blood and why some of these proteins should be in a high concentration and others in a low concentration, and finally what the measure of probability in the test result means. One interviewed person said, "First and foremost, when you do the combined test I would like to know what is the answers you get, what the phrase 'the probability' really means? Since you could get really frightened. A lot of people get frightened when they hear the number 'one in two hundred'. Then you have to think statistically in percent, how great is the risk in percent?" One interviewed person conveyed that it is relevant to also get information about amniocentesis as well as chorionic villus sampling when being informed about the combined test, since invasive testing can follow as a consequence of the combined test result.

Regarding amniocentesis, not all parents had perceived receiving any information about this invasive foetal diagnostics method. Among those who had received information, some parents were very satisfied with the information, while others felt that they had not received much information at all. One interviewed person wished that she had been informed about which time point amniocentesis and chorionic villus sampling are done, since she did not receive any information about this.

Some parents felt unclear which other foetal diagnostics methods were available besides the second trimester ultrasound diagnostics scan, as well as the time point and purposes of these tests. One interviewed person said, "I felt like we got a lot of information about the second trimester ultrasound diagnostics scan, but nothing about the rest."

Several parents, mostly the women in the couples interviewed, conveyed a difficulty of completely believing in the pregnancy until seeing the foetus on a screen during an ultrasound examination. For some interviewed parents, the second trimester ultrasound diagnostics scan was the first time they saw the foetus. Other couples had already had an early ultrasound examination performed prior to the second trimester ultrasound diagnostics scan. Some of the parents who had not done an early ultrasound examination said that they wished that they would have received more information about it; including information that it exists, information about the possibility to do an early ultrasound examination conducted in private management if one pays out-of-pocket, as well as information what can be seen at an early ultrasound examination. Some of the parents who had done an early ultrasound examination 
wished that they had been provided with more information. One interviewed person described how she did not feel prepared when she went to have the early ultrasound examination, regarding what she would be able to see.

\subsection{Varying pre-existing knowledge in order to ask questions}

Several parents mentioned that they maybe should have asked more questions themselves during the visit at the antenatal clinic, in order to get more clarity about foetal diagnostics. Though some parents also stated that it is difficult to know which questions to ask when one does not have enough knowledge in the subject. That is, they reflected that they cannot know what information is missing, when they do not know that that information exists. One interviewed person said, "It feels like something that you realize much later on, that: 'Ah... this is something that we would have needed to be informed about!' I am not aware of until later when I know that it potentially could have been given to me." One of the interviewed parents emphasised the importance of being able to discuss subjects that can be difficult to understand with the midwife at the antenatal clinic, such as the quota and measure of probability provided from a combined test in comparison to the risk connected to having an amniocentesis.

\section{The midwife has a great impact on the information perceived}

The interview data showed that the midwife's attitude, clarity, as well as an openness and susceptibility for questions has an impact on how information on foetal diagnostics is perceived. A challenge for the midwife is finding a balance regarding how much information should be given and increasing worry among parents.

\subsection{Varying opinions with respect to the midwife's attitude}

Some of the parents perceived that their midwife conveyed the information regarding the methods used in foetal diagnostics with a completely neutral attitude and that the midwife did not seem to have an opinion about whether the parents should undergo a certain diagnostic test. Other parents stated that they felt that the midwife had an opinion about whether the couple should take a certain diagnostic test. For example, one interviewed person said, "I got the feeling that she didn't think that we needed to do it..." and "I got the feeling that she was obliged to ask us that question, but not that she really thought that we should do it." One interviewee said that she did not perceive the midwife as neutral, though she believed that the midwife herself thought that she was perceived as neutral: "...She probably thought that she presented it in a pretty neutral way, but her opinion was clear." One interviewed person stated that she did not feel that it was a negative thing that the midwife seemed to have an opinion of her own, namely that 
the couple should not take a certain diagnostic test, since the woman was inclined to think the same thing herself before the visit at the antenatal clinic. Thus, the opinion of the midwife was in line with her own and the interviewed person perceived it as positive. Though the same interviewed person also stated that she might not have appreciated the non-neutral attitude from the midwife if the midwife's opinion had been different from her own. One of the parents who felt that the midwife did not have any opinion regarding whether the parents should take a certain diagnostic test said, "... I thought that she was completely neutral. She even said that 'I have to inform you about this, but I will not have any opinion about your decision.' I know she said that. "It is completely up to you."

\subsection{Sufficient and insufficient susceptibility and possibility to ask questions}

Some parents were very satisfied with the way the midwife presented the information concerning methods used in foetal diagnostics and also felt that there was an openness/receptiveness for questions in general. One interviewed person said, "...If there were something we would have liked to ask in particular about, we had the possibility" and "... I feel that if there would have been something, I could always call them and ask." Only one couple mentioned that their midwife, after giving the information concerning foetal diagnostic methods, gave the couple time to think about their options for a few days before making a decision. The couple appreciated that they were given this time to think: "...She gave us the information and then we got some time to think... Not a lot of time, but still a couple of days or a weekend or something like that. Then we had the possibility to call her, if we wanted to do it, and she would fix it." Other parents said that they would have wished that the midwife showed a greater openness for questions and felt that the visit at the antenatal clinic and with the midwife was too short for questions and sufficient explanations: "... There was very little time for information or questions and that was not so good."

\subsection{Requests of more clarity and a need to look for own information}

Some parents said that they had trouble remembering what kind of information they had received, or that they had trouble remembering if the information they have comprehended had been obtained from the midwife or from someone else. One interviewee wished that the midwife would have expressed the information more clearly and explicitly: "The midwife could rather have explained one thing too much than too little, so that you could feel that you knew more at the end of the visit than you did when you first came... She [the midwife] could by all means talk to me like a child, about these tests, I would not mind that at all... Even if she says something she thinks is basic, it might have taught me something."Some of the parents expressed that they had felt a need to look for information on their own after the visit with the midwife at the antenatal clinic. This was done by searching the internet or by asking family and friends. One interviewed person said, "I would not have managed if I had not been able to look it up myself. I read 
everything from research articles to Familjeliv's [internet-based webpage in Sweden where parents can freely write their own stories] comments on how they have done at their combined test. So, it is information from all levels. If I did not have the possibility to do this, I would have been sitting here totally without knowing anything/without any knowledge..." One couple was completely satisfied with the amount of information they received from the midwife at the antenatal clinic, but still looked for information on their own on the internet. So even though they felt a need to search for information on their own, they did not expect to get any further information from the midwife: "...I think that it is something you do automatically when you hear things... It is probably something that comes with our generation, that you do not accept everything you hear, you want to find out for yourself... When it comes to combined tests and things like that, because you want as much information as possible." Another interviewed person mentioned that it would have been even more difficult to get all of her questions answered if she had been from another country: "If I had not been Swedish and would have come here and not having access to the internet in the same way as I do now and not being able to read in English at different webpages, then one would have had a lot of questions."

\subsection{A balance regarding how much information should be given to decrease worry among parents}

Some parents expressed that they felt worried after the visit with the midwife at the antenatal clinic, since they had not fully understood the information given or did not feel that they had been sufficiently informed. One interviewed person said: "You get a bit worried: 'Why do they mention this? Is it something we ought to do?' ... That you could do it in different weeks and.. it was very.. like ..unclear about that." One interviewee felt that she would have liked to have more information about amniocentesis and chorionic villus sampling, but also stated that there might be a risk that the more one hears about different methods used in foetal diagnostics, the more inclined parents might be to think that it is more common with aberrations than it actually is and that the testing is something you ought to do. One interviewed person was dissatisfied with the way the midwife provided information about amniocentesis, since receiving the information that amniocentesis could cause a miscarriage made the woman feel scared. On the contrary, other parents expressed that more thorough information could decrease anxiety. One interviewee said: "For me, rather more than less [information]. I would not have managed if I had not been able to look it up myself... Then I would have been sitting there without knowing and that could be difficult for some mothers, they feel worried."

\section{Discussion}

This interview study found a substantial variation in how women and their partners perceived the information given about foetal diagnostics at the antenatal clinic. The differences were considerable regarding the level of information perceived about the different diagnostic methods, the voluntariness of prenatal testing, and the possibility and possible consequences of abnormal findings. The variation was further related to the parents' reported need of improved information, which was in turn related to the level 
of information provided and their own pre-existing knowledge. The midwife's attitude, openness for questions, time for explanations, and the balance between providing enough information to support, but not to worry the parents too much played an important role.

Earlier studies have shown that information provided before the second trimester ultrasound diagnostics scan is often insufficient $(4,16-18)$. This is unfortunate since sufficient information is needed for the parents to be able to make a well-informed choice about whether to undergo the examination (14). In our study, some of the parents perceived that they had been provided sufficient information about the examination, while others felt that they had not. Requests for more meticulous information regarding what will be able to be seen during the second trimester ultrasound diagnostics scan, what the midwife will validate, and how the examination will be carried out, were expressed. The result of this study can therefore be considered to be in accordance with earlier studies (4-6), unfortunately indicating insufficient progress in this area in Sweden. Some parents conveyed that it merely felt like it only was a matter of booking a date for the scan, rather than experiencing being informed about the voluntary procedure. This highlights the importance and lack of a clinical guideline on how to give information concerning foetal diagnostics in a non-directive way (19). One reason for the lack of information regarding the ultrasound examination could be that the procedure is not considered to involve any risks and many parents are positive towards the examination as an opportunity to experience visual confirmation of the foetus's existence. Several parents mentioned that they had difficulties believing in the pregnancy before getting it visually confirmed during an ultrasound examination, which of course could be a strong contributing factor for parents choosing to undergo the examination. It is therefore of extra importance to adequately inform the parents about the procedure to ensure that its purpose, limitations and voluntariness are clear to the parents.

In an earlier study, it was reported that a significant number of women could not recall being informed by any professional that malformations could be detected during the routine second trimester ultrasound scan (5). In our study, several parents stated that they had not perceived information about the possibility of abnormal findings. Some of these parents also expressed that they understood that the second trimester ultrasound diagnostics scan could reveal abnormal findings, even if they had not perceived being informed about it. It is stated in the directions and general advices from the Swedish National Board of Health and Welfare that each woman should be informed that the methods used in foetal diagnostics can reveal abnormal findings (2). Some of the parents in this study stated that they would have missed that information if it had not been given to them. That information about the possibility to detect abnormal findings is not always provided could be due to the fact that the midwives do not want to frighten the parents by mentioning the possibility of abnormal findings (20), but the absence of such information could also create worry among parents. The information given at the antenatal clinic should be clear about the possibility that malformations can be detected, although the risk is low, and preferably also including information about what would happen next if such a situation would occur.

It is important to provide adequate information about the limitations of the second trimester ultrasound diagnostics scan. Some parents in our study stated that the purpose of the second trimester ultrasound 
diagnostics scan was to "check everything" and others used the words, "to check that everything looks okay", which is in line with other previous studies (21). It is difficult to know what the parents fully mean when using the word everything as in the foregoing sentences, but it is certainly of great importance that the parents are informed about the fact that the second trimester ultrasound diagnostics scan is not able to detect every possible malformation or aberration. In earlier studies by Garcia et al. 2002, and Lalor et al. 2007, it was found that women often lack information about the purposes for which an ultrasound scan is being done as well as the technical limitations of the procedure $(7,8)$. It was also shown that most of the participating women had expectations that exceeded the purpose and capability of the examination (7). As exemplified above, the answers in our study show a tendency towards the same result as in these previous studies. It should, however, be mentioned that the information perceived about technical limitations of the procedure was not itself one of the main questions examined in this study.

The answers in our study varied regarding how information about the voluntariness of undergoing the second trimester ultrasound diagnostics scan was perceived. Several parents stated that they had perceived such information, but other parents stated that they had not. It is unfortunate that not all parents have perceived information that the second trimester ultrasound diagnostics scan is voluntary. Even though some parents stated that they presumed that the examination was voluntary even if they had not perceived this information, every woman should be provided information that the methods used in foetal diagnostics is voluntary, as stated in directions and general advices of the Swedish National Board of Health and Welfare (2).

Larsen et al. 2000 found that literature/newspaper/TV, family, and friends played an important role as sources for general information for pregnant women undergoing a pregnancy-related ultrasound examination (3). The results of our study showed that some of the interviewed parents felt a need to look for information on their own after the visit with the midwife at the antenatal clinic. The information was obtained by asking family and friends, as well as by searching the internet. The need to search for information on their own was not only limited to information regarding the second trimester ultrasound diagnostics scan, but also involved answering questions about other methods used in foetal diagnostics. One interesting finding was that some parents stated that they did not expect to get all information that they wanted regarding foetal diagnostics from the midwife at the antenatal clinic. Instead, they felt that the search for information on their own was a part of their generation and upbringing. Other parents, however, expressed that they felt safer obtaining all information they needed from the midwife at the antenatal clinic. The finding further shows great variety related to the parents' pre-existing knowledge; some found the information to be too basic while others believed it was too advanced. One conclusion that can be drawn from these contrasting answers is that it is important to adapt the information to each woman and partner $(22,23)$. One of the findings of our study was that some parents expressed a need for a greater openness for questions from the midwife as well as more time for questions and discussions during the visit with the midwife at the antenatal clinic. Wätterbjörk et al. 2015 showed that repeated visits with possibility to ask more questions were appreciated (20). With more time and a greater receptiveness for the parents' thoughts and questions, it might be possible to reach an adequate level of information for each and every woman and partner. 
Of great importance is also that the midwife at the antenatal clinic provides oral information in a nondirective way (19) with consideration taken to the level of the parents' prior knowledge and that an openness is shown to the parents' thoughts and questions. Some of the interviewed parents stated that they felt that their midwife did not have a completely neutral attitude concerning whether the parents should undergo a certain diagnostic test, which also was shown in the study by Tsouroufli et al 2011 (24). Irrespective of the age of the pregnant woman, it is important that all parents receive equal and adequate information about foetal diagnostics provided in a neutral way.

Providing information about foetal diagnostics to the pregnant woman and her partner can be very challenging for the midwife (24). Wätterbjörk et al. 2015 stated that there are three different patterns of decision making that the pregnant woman and her partner use when it comes to foetal diagnostics and that this demands individualized information (20). Since the findings of this study also suggest that parents prefer being provided information in different ways as regards to written and oral information, it is possible that a standardised video material containing information about foetal diagnostics could be an effective complement to the information provided today. This would ensure that all parents receive the same information and that the quality of the information would be secured, which is important since it can be difficult to keep all personnel up to date at an adequate level of knowledge in an area of expertise with such rapid development. Several parents stated that they appreciated being able to read the written material at home in peace and quiet after the visit with the midwife at the antenatal clinic and also when a certain examination was approaching. In addition to the video material, a standardised brochure could also be provided to all parents. Further a clinical guideline for the midwifes to make sure that no vital information is left out and that the information preferably is given in the same way would also be desirable.

\section{Methodological considerations}

This study was conducted as a qualitative interview study. Ten pregnant women and seven partners participated in the study and hence the collected material was based on interviews with 17 parents. The study design as an interview study do not claim to describe the situation for all parents in the situation of the participants. The purpose of the study was to give a description of the experiences of the parents participating in the study and the results should not to be generalised. Their age, pre-existing knowledge and experience as well as likelihood of a chromosomal aberration in their individual cases can of course affect the answers. A qualitative study can, however, give a deeper understanding of the experiences (15) of the parents interviewed and, in that way, enlighten important details about how information provided about foetal diagnostics at the antenatal clinic is perceived. As such, this study can provide data for improving the information given in the antenatal clinic.

\section{Conclusions}

The results of this study confirm earlier studies' findings that inadequate information about foetal diagnostics is provided to pregnant women and their partners at the antenatal clinic and hence 
insufficient progress has been made in this area although new methods in foetal diagnostics are added at a quick pace. Thus, we conclude that there still is need for improvements regarding the information provided about foetal diagnostics at the antenatal clinics today. The information should be explicit concerning purpose, the voluntariness, limitations and possible consequences of the methods used in foetal diagnostics. Sufficient time available for questions, explanations and discussions of the subject is important, as well as an openness for questions from the midwife. Since every parent is different and prefers to be provided information in different ways, a standardised video material could be a good complement to the oral and written information provided at the antenatal clinic today and would also ensure autonomy and equality for each and every patient. As new methods for foetal diagnostics are introduced into routine health care, it is of great importance that the quality of the information provided at the antenatal clinic is sufficient, since the risks and difficulties with the practical execution of the prenatal testing decreases and it is easier for parents to accept a test without careful consideration. The diversity in answers among the participants in this study highlights the importance of considering the parents' prior knowledge and their individual thoughts and questions when giving information about foetal diagnostics.

\section{Abbreviations}

NIPT = Non-invasive prenatal testing

SBU $=$ The Swedish Agency for Health Technology Assessment and Assessment of Social Services

\section{Declarations}

\section{Ethics approval and consent to participate}

The study was performed in accordance with the Declaration of Helsinki and approved by the ethical committee of Gothenburg (861-15). Informed consent was obtained from all participants. Parents were provided with written and oral information stating that all participation in the study was voluntary and that the participant could at any time choose to interrupt the participation of the study, without the medical care of the participant being affected in any way. Participants were also notified that if they in any way felt discomfort during or after the interview, contact with a doctor, midwife or counsellor could be provided.

\section{Consent for publication}

Not applicable

\section{Availability of data and materials}

The datasets generated and/or analysed during the current study are not publicly available due confidentiality under Swedish law, but are available encoded from the corresponding author on 
reasonable request.

\section{Competing interests}

The authors have no conflicts of interest. Please refer to Funding.

\section{Funding}

Lindhes Advokatbyrå (Stiftelsen Castegrens minne) (YC, LA2015-0338) provided financial support for ethical application and material. Grants from the Swedish state under the agreement between the Swedish government and the county councils, the ALF agreement (YC, ALFGBG-77860) financed time for performing research.

\section{Authors' contributions}

YC provided the outline for the study. YC, IL, and PS wrote the protocol. PS performed the interviews. PS and IL processed the data. All authors have revised the manuscript several times.

\section{Acknowledgements}

The authors would like to thank the midwives at the ultrasound unit at the Department of Obstetrics and Gynaecology at Sahlgrenska University Hospital, Gothenburg, for their support, as well as the kind parents who chose to participate in the study and share their experiences.

\section{References}

1. Midwives. TSAo. The Qualifications of registered midwives. 2018.

2. Socialstyrelsen. SOSFS 2012:20 Foetal diagnostics and preimplantation genetic diagnosis (Fosterdiagnostik och preimplantatorisk genetisk diagnostik) 2012 [2015-12-09]. Available from: http://www.socialstyrelsen.se/publikationer2012/2012-12-34.

3. Larsen T, Nguyen TH, Munk M, Svendsen L, Teisner L. Ultrasound screening in the 2nd trimester. The pregnant woman's background knowledge, expectations, experiences and acceptances. Ultrasound Obstet Gynecol. 2000;15(5):383-6.

4. Routine Ultrasound during Pregnancy (Rutinmässig ultraljudsundersökning under graviditet). Stockholm: Statens beredning för utvärdering av medicinsk metodik (SBU); 1998.

5. Crang-Svalenius E, Dykes AK, Jörgensen C. Organized routine ultrasound in the second trimester-one hundred women's experiences. J Matern-Fetal Invest. 1996;6(4):219-22.

6. Eurenius K, Axelsson O, Gallstedt-Fransson I, Sjoden PO. Perception of information, expectations and experiences among women and their partners attending a second-trimester routine ultrasound scan. Ultrasound Obstet Gynecol. 1997;9(2):86-90.

7. Lalor JG, Devane D. Information, knowledge and expectations of the routine ultrasound scan. Midwifery. 2007;23(1):13-22. 
8. Garcia J, Bricker L, Henderson J, Martin MA, Mugford M, Nielson J, et al. Women's views of pregnancy ultrasound: a systematic review. Birth. 2002;29(4):225-50.

9. Georgsson Ohman S, Waldenstrom U. Second-trimester routine ultrasound screening: expectations and experiences in a nationwide Swedish sample. Ultrasound Obstet Gynecol. 2008;32(1):15-22.

10. Ekelin M, Crang-Svalenius E, Dykes AK. A qualitative study of mothers' and fathers' experiences of routine ultrasound examination in Sweden. Midwifery. 2004;20(4):335-44.

11. Fan HC, Blumenfeld YJ, Chitkara U, Hudgins L, Quake SR. Noninvasive diagnosis of fetal aneuploidy by shotgun sequencing DNA from maternal blood. Proc Natl Acad Sci U S A. 2008;105(42):16266-71.

12. Norton ME, Jacobsson B, Swamy GK, Laurent LC, Ranzini AC, Brar H, et al. Cell-free DNA analysis for noninvasive examination of trisomy. N Engl J Med. 2015;372(17):1589-97.

13. Iwarsson E, Jacobsson B, Dagerhamn J, Davidson T, Bernabe E, Heibert Arnlind M. Analysis of cellfree fetal DNA in maternal blood for detection of trisomy 21, 18 and 13 in a general pregnant population and in a high risk population - a systematic review and meta-analysis. Acta Obstet Gynecol Scand. 2017;96(1):7-18.

14. Crombag NM, Bensing JM, ledema-Kuiper R, Schielen PC, Visser GH. Determinants affecting pregnant women's utilization of prenatal screening for Down syndrome: a review of the literature. $J$ Matern Fetal Neonatal Med. 2013;26(17):1676-81.

15. Graneheim U, Lundman, B. . Qualitative Content Analysis in Nursing Research: Concepts, Procedures and Measures to Achieve Trustworthiness. Nurse Educ Today. 2004;24(2):105-12.

16. Ekelin M, Crang-Svalenius E, Nordstrom B, Dykes AK. Parents' experiences, reactions and needs regarding a nonviable fetus diagnosed at a second trimester routine ultrasound. J Obstet Gynecol Neonatal Nurs. 2008;37(4):446-54.

17. Kaila-Behm A, Vehvilainen-Julkunen K. Ways of being a father: how first-time fathers and public health nurses perceive men as fathers. Int J Nurs Stud. 2000;37(3):199-205.

18. Finnbogadottir H, Crang Svalenius E, Persson EK. Expectant first-time fathers' experiences of pregnancy. Midwifery. 2003;19(2):96-105.

19. Ahmed S, Bryant LD, Cole P. Midwives' perceptions of their role as facilitators of informed choice in antenatal screening. Midwifery. 2013;29(7):745-50.

20. Watterbjork I, Blomberg K, Nilsson K, Sahlberg-Blom E. Pregnant women's and their partners' perception of an information model on prenatal screening. Prenat Diagn. 2012;32(5):461-6.

21. Ternby E, Axelsson O, Anneren G, Lindgren P, Ingvoldstad C. Why do pregnant women accept or decline prenatal diagnosis for Down syndrome? J Community Genet. 2016;7(3):237-42.

22. Midwives) IICo. International code of ethics for midwives. 2014.

23. Renfrew MJ, McFadden A, Bastos MH, Campbell J, Channon AA, Cheung NF, et al. Midwifery and quality care: findings from a new evidence-informed framework for maternal and newborn care. Lancet. 2014;384(9948):1129-45. 
24. Tsouroufli M. Routinisation and constraints on informed choice in a one-stop clinic offering first trimester chromosomal antenatal screening for Down's syndrome. Midwifery. 2011;27(4):431-6. 